University at Albany, State University of New York

Scholars Archive

Educational \& Counseling Psychology Faculty

Scholarship

Educational \& Counseling Psychology

$11-2011$

\title{
Changes in Protective Behavioral Strategies and Alcohol Use among College Students
}

Jessica Martin

University at Albany, State University of New York, jlmartin@albany.edu

M. Dolores Cimini

University at Albany, State University of New York, dcimini@albany.edu

The University at Albany community has made this article openly available.

Please share how this access benefits you.

Follow this and additional works at: https://scholarsarchive.library.albany.edu/edpsych_fac_scholar

Part of the Medicine and Health Sciences Commons

\section{Recommended Citation}

Martin, Jessica and Cimini, M. Dolores, "Changes in Protective Behavioral Strategies and Alcohol Use among College Students" (2011). Educational \& Counseling Psychology Faculty Scholarship. 21.

https://scholarsarchive.library.albany.edu/edpsych_fac_scholar/21

\section{(c) (†) $\ominus$}

This work is licensed under a Creative Commons Attribution-NonCommercial-No Derivative Works 4.0 International License.

\section{Rights Statement}

C. IN COPYRIGHT

This Article is brought to you for free and open access by the Educational \& Counseling Psychology at Scholars Archive. It has been accepted for inclusion in Educational \& Counseling Psychology Faculty Scholarship by an authorized administrator of Scholars Archive.

Please see Terms of Use. For more information, please contact scholarsarchive@albany.edu. 


\title{
Changes in Protective Behavioral Strategies and Alcohol Use among College Students*
}

\author{
Matthew P. Martens ${ }^{a}$, Jessica L. Martin ${ }^{b}$, Andrew K. Littlefield ${ }^{c}$, James G. Murphyd ${ }^{d}$, and M. \\ Dolores Ciminie \\ Matthew P. Martens: martensmp@missouri.edu; Jessica L. Martin: jessIm8@gmail.com; Andrew K. Littlefield: \\ akl9af@mail.mizzou.edu; James G. Murphy: jgmurphy@memphis.edu; M. Dolores Cimini: dcimini@uamail.albany.edu \\ a Department of Educational, School, and Counseling Psychology, 16 Hill Hall, University of \\ Missouri, Columbia, MO 65211 \\ b Department of Educational and Counseling Psychology, ED 220, University at Albany-SUNY, \\ Albany, NY 12222 \\ c Department of Psychological Sciences, Psychology Building 105, University of Missouri- \\ Columbia, Columbia, MO 65211 \\ d Department of Psychology, Psychology Building 348, University of Memphis, Memphis, TN \\ 38152 \\ e University Counseling Center, University at Albany-SUNY, 400 Patroon Creek Blvd, Albany, NY \\ 12206
}

\section{Abstract}

Background-Protective behavioral strategies (PBS) are specific cognitive-behavioral strategies designed to reduce alcohol consumption and resulting negative consequences. A host of studies have examined the cross-sectional relationship between such strategies and alcohol use in the high-risk population of United States college students, but prospective studies on the construct are lacking. The primary purposes of this study were to determine if PBS use prospectively predicted subsequent alcohol use/alcohol-related problems and if changes in PBS use were associated with less alcohol use and fewer problems.

Methods-Data were examined from 521 heavy drinking college students (60\% male, 84\% White, mean age $=18.9$ years). Participants completed questionnaires assessing alcohol use, alcohol-related problems, and PBS use at baseline, 6-month, and 12-month follow-ups.

Results-Analysis of residualized change scores indicated that increases in some PBS across time were associated with less alcohol use and fewer alcohol-related problems at follow-up. Findings regarding the prospective relationship between PBS use and subsequent alcohol use/ problems were equivocal.

\footnotetext{
*A supplementary table for this manuscrpt can be viewed by entering doi\#...

(C) 2011 Elsevier Ireland Ltd. All rights reserved.

Correspondence concerning this article should be addressed to Matthew P. Martens; Department of Educational, School, and Counseling Psychology, 16 Hill Hall, University of Missouri, Columbia, MO 65211; martensmp@ missouri.edu; (573) 882-3382 (t), (573) 884-5989 (f).

${ }^{2} \mathrm{~A}$ table including the descriptive statistics for each main study variable at each time point is provided in the supplementary material. Publisher's Disclaimer: This is a PDF file of an unedited manuscript that has been accepted for publication. As a service to our customers we are providing this early version of the manuscript. The manuscript will undergo copyediting, typesetting, and review of the resulting proof before it is published in its final citable form. Please note that during the production process errors may be discovered which could affect the content, and all legal disclaimers that apply to the journal pertain.
} 
Discussion-Results from the study suggest that PBS may have value in alcohol-related interventions among college students. Clinicians who help clients increase their use of PBS may help those clients increase the probability of drinking less and experiencing fewer alcohol-related problems in the future.

\section{Keywords}

Alcohol; College Student; Protective Behavioral Strategies

\section{Introduction}

College students in the United States are at high risk for heavy alcohol consumption and resulting negative consequences (Hingson et al., 2009; Johnston et al., 2009). Moreover, heavy drinking among college students has been associated with serious consequences for other students and academic institutions themselves (Perkins, 2002; Wechsler et al., 2002).

Researchers have attempted to identify factors that reduce alcohol-related risks among this population. One factor that has received recent attention is protective behavioral strategies (PBS), or specific cognitive-behavioral strategies designed to reduce risky drinking (Martens et al., 2004). Examples of PBS include "Avoid drinking games" and "Use a designated driver" (Martens et al., 2005). Cross-sectional studies among college students have found that PBS use was inversely associated with alcohol use and related problems (Benton et al., 2004; 2006; Delva et al., 2004; Haines et al., 2006; Martens et al., 2004; 2005; 2007; Walters et al., 2007). However, studies have not examined whether or not PBS use predicts future alcohol-related outcomes. Establishing this would provide evidence regarding the directionality of the relationship between PBS and alcohol use (Wegener and Fabrigar, 2000).

A second important question is whether or not changes in PBS use over time are associated with less alcohol use and fewer alcohol-related problems. This question differs from establishing a prospective relationship in that it seeks to determine if changes in PBS use, rather than absolute amount of use at one time point, are associated with alcohol-related outcomes. PBS have not been described as having stable trait-like properties, as research has conceptualized them as factors that could be taught or modified (e.g., Martens et al., 2004). Therefore, how changes in PBS are associated with subsequent drinking-related outcomes may be a more relevant question than whether PBS use at a fixed time-point predicts subsequent outcomes. At least two published studies have attempted to address this question, both of which showed that changes in PBS use mediated the effectiveness of brief motivational interventions (Barnett et al., 2007; Larimer et al., 2007). These studies, though, were limited by two important factors: both used measures of PBS that have not been well validated and both examined a composite PBS score, whereas research has suggested that distinct factors of the construct exist (Martens et al., 2007).

The purpose of the present study was to therefore address two major research questions. First, is PBS use a prospective predictor of alcohol use and alcohol-related problems? Second, are changes in PBS use associated with changes in alcohol consumption and alcohol-related problems? We hypothesized that both baseline PBS use and changes in PBS use over time would be inversely associated with follow-up alcohol use and alcohol-related problems. 


\section{Methods}

\subsection{Participants}

Eligible participants were 685 undergraduate students who were referred to an alcohol intervention program as a consequence of committing an alcohol-related infraction, threefourths of whom (76.1\%) completed follow-up questionnaires at one or more of the followup points and were included in this study. The majority of participants were male $(60.3 \%)$, and White $(83.9 \%)$. The mean age was 18.9 years (range $=18-22)$. Women were more likely to provide follow-up data than men $(81 \%$ vs. $73 \%)$. After controlling for gender differences there were no baseline differences in alcohol use, alcohol-related problems, or PBS use between those who did and did not provide follow-up data.

\subsection{Measures}

PBS use was assessed via the Protective Behavioral Strategies Scale (PBSS) (Martens et al., 2005), which asks participants about their use of specific protective strategies. Responses range from 1 (never) to 6 (always) and three subscale scores are computed: Manner of Drinking (MOD: 7 items), which focuses on reducing specific risky alcohol consumption strategies, Stopping/Limiting Drinking (SLD: 5 items), which focuses on drinking reduction strategies that involve planning one's evening in advance or more general alcohol reduction techniques, and Serious Harm Reduction (SHR: 3 items), which focuses on strategies designed to limit potentially serious alcohol-related harms. Alpha coefficients in the present study ranged from .67 (SHR baseline) to .92 (SLD 12-month follow-up). Alcohol consumption was assessed using a version of the Daily Drinking Questionnaire (Collins et al., 1985). Participants were asked to estimate the average number of drinks they consumed for each day of the week over the past month, which was used to calculate average number of drinks per week. Alcohol-related problems over the past 6 months were assessed with the Rutgers Alcohol Problem Index (RAPI) (White and Labouvie, 1989). The RAPI assesses 23 problems measured on a scale ranging from 0 (never) to 4 (more than 10 times). We also included two additional items assessing drinking and driving. The internal consistency of the measure for the present sample ranged from .91 (Baseline) to .97 (12-month follow-up).

\subsection{Procedures}

Data were collected as part of a larger research project examining the efficacy of three group interventions delivered to judicially mandated students (Cimini et al., 2009). Students who committed an alcohol-related infraction had the opportunity to participate in the project and receive either one of the study interventions or an intervention of similar duration provided by the university counseling center. Those who chose to participate in the project provided consent and completed the baseline measures. Follow-up questionnaires were completed at 6 and 12 - months post-intervention.

\subsection{Data Analysis}

A series of hierarchical regression analyses were utilized to answer our research questions. Gender and baseline scores on the outcome variable in question were included in step 1 as covariates, as were follow-up drinks per week in analyses with alcohol-related problems as the outcome variable. The three scores from the PBSS subscales were then entered on step 2. To assess the prospective relationship between PBS use and alcohol use/problems we regressed the follow-up use or problems score on baseline scores from the three PBSS subscales. To determine whether or not changes in PBS use were associated with follow-up alcohol use/problems we regressed the follow-up use or problems score on the residualized change scores from the three PBSS subscales. We used the residualized change score rather than a simple difference score because the former are more reliable than the latter and 
account for baseline differences on the variable in question (MacKinnon, 2008).

Residualized change scores were calculated for each variable at each follow-up point by obtaining predicted values from a regression analysis for each based on baseline values (e.g., predicting 6-months drinks per week based on baseline drinks per week), and then subtracting the predicted score from the actual follow-up score (MacKinnon, 2008). A previous study (Cimini et al., 2009) showed that there were no intervention group differences on alcohol use, alcohol-related problems, or any of the PBSS subscales. Therefore, participants were collapsed across all conditions. 1 Four subjects with outliers on alcohol problems scores at the follow-ups (i.e., indicating that they experienced every problem $>10$ times) were deleted from those analyses.

\section{Results}

\subsection{Prospective Relationship Between PBS and Alcohol Outcomes}

Participants averaged between 17.14 and 18.32 drinks per week over the three time points. There were no significant differences over time except for the SHR subscale, which decreased across the time-points $(p<.01)^{2} .{ }^{2}$ Bivariate correlations among the study variables are presented in Table 1. Baseline PBSS scores were not associated with 6-month drinks per week, $\Delta F(3,463)=2.17, p=.09, \Delta R^{2}=.01$, but they were associated with 12month drinks per week, $\Delta F(3,354)=3.94, p=.01, \Delta R^{2}=.02$. Higher scores on the SLD subscale were associated with fewer drinks per week, $\beta=-.14, p=.01$. Despite a negative bivariate correlation between both baseline MOD and SHR scores and drinks per week at 12 months, both were positively associated with alcohol us in the regression equation ( $\beta=.13$, $p=.02$ and $\beta=.10, p=.04$, respectively). These findings are likely due to a suppressor effect (MacKinnon et al., 2000), given the relatively high correlations among the three PBSS subscales and between the subscales and baseline alcohol use. Further, the beta weights for each of the three subscales were not statistically significant when entered into the analysis without the other subscales. Baseline PBSS scores were also associated with 6-month alcohol-related problems, $\Delta F(3,449)=4.79, p<.01, \Delta R^{2}=.02$. Higher SHR scores were associated with fewer alcohol-related problems $(\beta=-.09, p=.05)$, whereas SLD scores were positively associated with alcohol-related problems $(\beta=.14, p=.01)$. Again, we believe that this latter finding is due to a suppressor effect given the positive bivariate correlation between the measures. Baseline PBSS scores were not associated with 12-month alcohol-related problems, $\Delta F(3,340)=0.60, p=.63, \Delta R^{2}=.00$.

\subsection{Relationship between Changes in PBS Use and Alcohol-Related Outcomes}

Changes in PBSS scores were associated with drinks per week at the 6-month follow-up, $\Delta F(3,451)=5.67, p<.01, \Delta R^{2}=.02$. This relationship was primarily due to changes on the MOD subscale, $\beta=-.16, p<.01$, with increased MOD scores associated with fewer drinks per week (see Table 2). At the 12-month follow-up PBSS scores were also associated with drinks per week, $\Delta F(3,341)=8.04, p<.01, \Delta R^{2}=.04$, with this relationship again due largely to changes in MOD scores, $\beta=-.22, p<.01$.

At the 6-month follow-up overall changes in PBSS subscale scores were associated with alcohol-related problems, $\Delta F(3,448)=2.70, p=.05, \Delta R^{2}=.01$, with this relationship primarily due to changes on SHR scale, $\beta=-.10, p=.02$. At the 12-month follow-up changes in PBSS subscale scores were also associated with alcohol-related problems, $\Delta F(3,337)=3.89, p=.01, \Delta R^{2}=.03$. Increases in SHR subscale scores were again associated with fewer alcohol-related problems, $\beta=-.18, p<.01$.

\footnotetext{
${ }^{1}$ Analyses that included intervention condition as a covariate yielded essentially identical findings as those that did not include intervention condition in the regression model.
} 


\section{Discussion}

The most consistent finding in this study was that increased PBS use from baseline to follow-up was associated with less alcohol use and fewer problems. Specifically, increases on the MOD subscale were associated with less alcohol use and increases on the SHR subscale were associated with fewer alcohol-related problems. These findings are consistent with cross-sectional research where we found that only the MOD and SHR subscales were uniquely associated with alcohol use/problems (Martens et al., 2005). Increasing PBS related to risky drinking practices (e.g., avoiding shots and drinking games) may be useful at reducing alcohol consumption, whereas increasing PBS that focus specifically on avoiding serious negative consequences associated with alcohol use (e.g., using a designated driver, knowing where your drink has been at all times) may be useful at reducing overall alcoholrelated harms. In contrast, increases on the SLD subscale were not associated with less alcohol use or fewer alcohol-related problems. Items on the SLD subscale assess strategies like planning one's drinking in advance, which may be difficult for many college students to follow through with. It is also possible that the strategies assessed on the SLD subscale are simply less effective at reducing alcohol consumption.

The pattern of findings from the analyses involving the prospective association between baseline PBS use and follow-up alcohol-related outcomes were inconsistent. In two instances PBSS subscales were associated with alcohol use/problems, but the direction of the relationship varied across subscales and some of these effects were likely an artifact of suppression. In the other instances PBSS scores were not associated with alcohol use/ problems. These inconsistent findings suggest that it is not absolute level of PBS use that is most important in predicting future drinking-related outcomes, but rather whether or not PBS use increases or decreases over time.

Limitations to this study include data collection at a single university and from participants who committed an alcohol-related infraction, all data were self report, and a relatively low response rate at follow-up. Despite these limitations the present study provides preliminary evidence that increasing the use of certain PBS is associated with less alcohol use and fewer alcohol-related problems among college students. Unlike other established risk factors PBS are teachable behaviors that can be directly targeted as part of interventions. As such, they are a promising mechanism of behavior change to include in alcohol use interventions.

\section{Supplementary Material}

Refer to Web version on PubMed Central for supplementary material.

\section{References}

Barnett NP, Murphy JG, Colby SM, Monti PM. Efficacy of counselor vs. computer-delivered intervention with mandated college students. Addict Behav. 2007; 32:2529-2548. [PubMed: 17707594]

Benton SL, Benton SA, Downey RG. College student drinking, attitudes toward risks, and drinking consequences. J Stud Alcohol. 2006; 67:543-551. [PubMed: 16736074]

Benton SL, Schmidt JL, Newton FB, Shin K, Benton SA, Newton DW. College student protective strategies and drinking consequences. J Stud Alcohol. 2004; 65:115-121. [PubMed: 15000510]

Cimini MD, Martens MP, Larimer ME, Kilmer JR, Neighbors C, Monserrat JM. Assessing the effectiveness of peer-facilitated interventions addressing high-risk drinking among judicially mandated college students. J Stud Alcohol Drugs Suppl. 2009; 16:57-66. [PubMed: 19538913]

Collins RL, Parks GA, Marlatt GA. Social determinants of alcohol consumption: the effects of social interaction and model status on the self-administration of alcohol. J Consult Clin Psychol. 1985; 53:189-200. [PubMed: 3998247] 
Delva J, Smith MP, Howell RL, Harrison DF, Wilke D, Jackson DL. A study of the relationship between protective behaviors and drinking consequences among undergraduate college students. J Am Coll Health. 2004; 53:19-26. [PubMed: 15266726]

Haines MP, Barker G, Rice RM. The personal protective behaviors of college student drinkers: evidence of indigenous protective norms. J Am Coll Health. 2006; 55:69-75. [PubMed: 17017302]

Hingson RW, Zha W, Weitzman ER. Magnitude of and trends in alcohol-related mortality and morbidity among US college students ages 18-25, 1998-2005. J Stud Alcohol Drugs Suppl. 2009; 16:12-20. [PubMed: 19538908]

Johnston, LD.; O’Malley, PM.; Bachman, JG.; Schulenberg, JE. NIH Publication No. 09-7403. National Institute on Drug Abuse; Bethesda, MD: 2008. Monitoring the Future National Survey Results on Drug Use, 1975-2008: Volume II, College Students and Adults Ages 19-50.

Larimer ME, Lee CM, Kilmer JR, Fabiano PM, Stark CB, Geisner IM, Mallett KA, Lostutter TW, Cronce JM, Feeney M, Neighbors C. Personalized mailed feedback for college drinking prevention: a randomized clinical trial. J Consult Clin Psychol. 2007; 75:285-293. [PubMed: 17469886]

MacKinnon, DP. Introduction to Statistical Mediation Analysis. Erlbaum; Mahwah, NJ: 2008.

MacKinnon DP, Krull JL, Lockwood CM. Equivalence of mediation, confounding, and suppression effect. Prev Sci. 2000; 1:173-181. [PubMed: 11523746]

Martens MP, Ferrier AG, Sheehy MJ, Corbett K, Anderson DA, Simmons A. Development of the Protective Behavioral Strategies Survey. J Stud Alcohol. 2005; 66:698-705. [PubMed: 16329461]

Martens MP, Pedersen ER, LaBrie JW, Ferrier AG, Cimini MD. Measuring alcohol-related protective behavioral strategies among college students: further examination of the Protective Behavioral Strategies Scale. Psychol Addict Behav. 2007; 21:307-315. [PubMed: 17874881]

Martens MP, Taylor KK, Damann KM, Page JC, Mowry ES, Cimini MD. Protective factors when drinking alcohol and their relationship to negative alcohol-related consequences. Psychol Addict Behav. 2004; 18:390-393. [PubMed: 15631613]

Perkins HW. Surveying the damage: a review of research on consequences of alcohol misuse in college populations. J Stud Alcohol Suppl. 2002; 14:91-100. [PubMed: 12022733]

Walters ST, Roudsari BS, Vader AM, Harris RT. Correlates of protective behavior utilization among heavy-drinking college students. Addict Behav. 2007; 32:2633-2644. [PubMed: 17669596]

Wechsler H, Lee JE, Kuo M, Seibring M, Nelson TF, Lee H. Trends in college binge drinking during a period of increased prevention efforts. J Am Coll Health. 2002; 50:203-217. [PubMed: 11990979]

Wegener, DT.; Fabrigar, LR. Analysis and design for non-experimental data: addressing causal and non-causal hypothesis. In: Reis, H.; Judd, CM., editors. Handbook of Research Methods in Social and Personality Psychology. New York, NY: Cambridge, New York; 2000. p. 412-450.

White HR, Labouvie EW. Towards the assessment of adolescent problem drinking. J Stud Alcohol. 1989; 50:30-37. [PubMed: 2927120] 


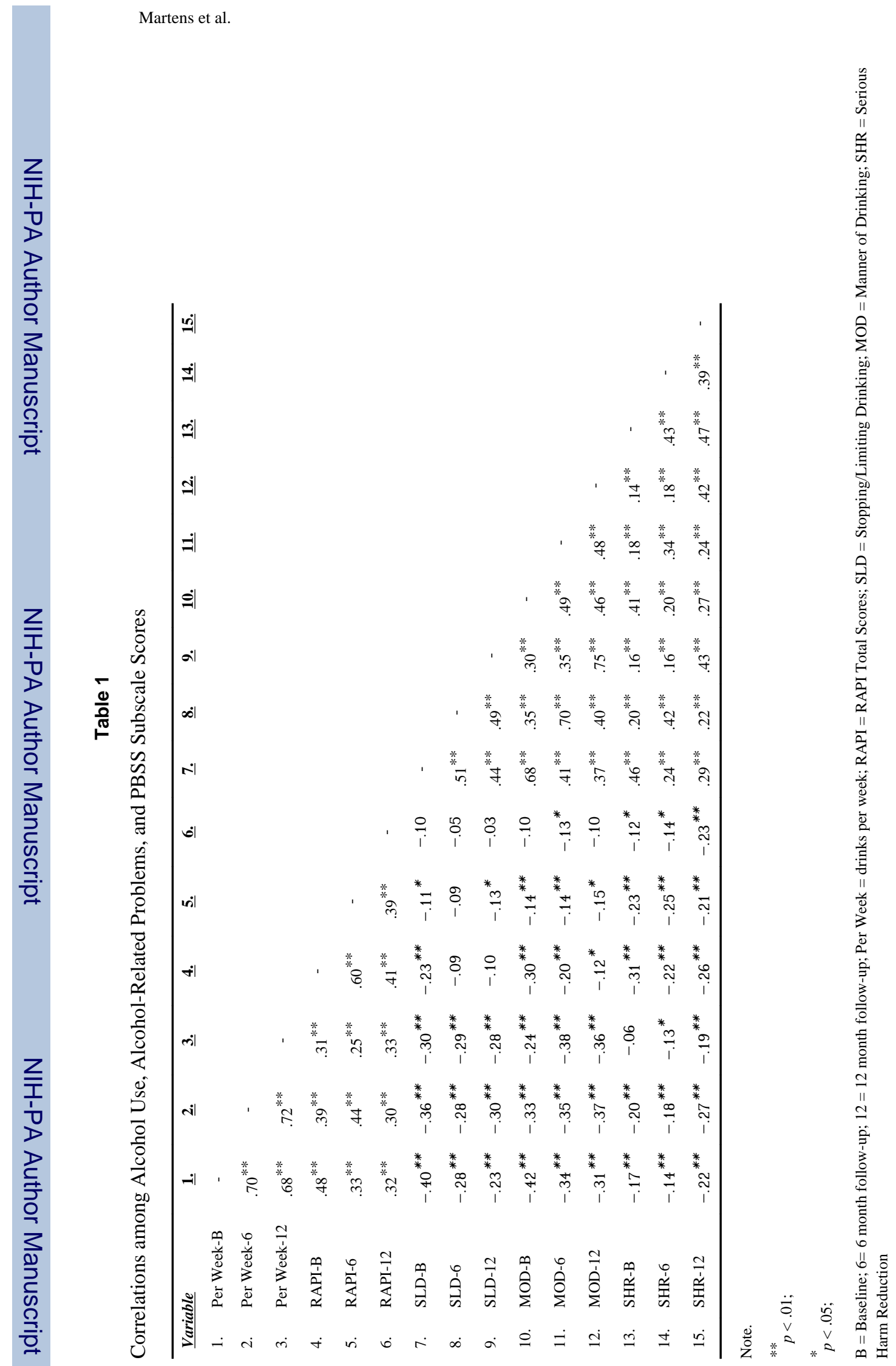

Page 7 
Table 2

Relationship between Changes in PBS Scores and Follow-up Alcohol Use/Problems

\begin{tabular}{|c|c|c|c|c|}
\hline Variable & B & SE B & $\boldsymbol{B}$ & $p$ \\
\hline & \multicolumn{4}{|c|}{ 6-Month Drinks/Week } \\
\hline SLD Change & -0.76 & 0.56 & .06 & .17 \\
\hline MOD Change & -2.43 & 0.65 & -.16 & .00 \\
\hline \multirow[t]{2}{*}{ SHR Change } & -0.24 & 0.43 & -.02 & .58 \\
\hline & \multicolumn{4}{|c|}{ 12-Month Drinks/Week } \\
\hline SLD Change & 0.49 & 0.65 & .04 & .45 \\
\hline MOD Change & -3.30 & 0.84 & -.22 & .00 \\
\hline \multirow[t]{2}{*}{ SHR Change } & 0.04 & 0.47 & .00 & .93 \\
\hline & \multicolumn{4}{|c|}{ 6-Month Alcohol Problems } \\
\hline SLD Change & -0.42 & 0.56 & -.04 & .45 \\
\hline MOD Change & 0.58 & 0.65 & .04 & .37 \\
\hline \multirow[t]{2}{*}{ SHR Change } & -1.03 & 0.43 & -.10 & .02 \\
\hline & \multicolumn{4}{|c|}{ 12-Month Alcohol Problems } \\
\hline SLD Change & 1.23 & 0.77 & .11 & .11 \\
\hline MOD Change & -0.44 & 1.03 & -.03 & .67 \\
\hline SHR Change & -1.84 & 0.56 & -.18 & .00 \\
\hline
\end{tabular}

Note. Values represent the final step of the regression equation. $\mathrm{SLD}=$ Stopping/Limiting Drinking. MOD $=$ Manner of Drinking. SHR $=$ Serious Harm Reduction. 